\title{
La concentración del mercado de la auditoría en Perú*
}

\author{
Audit market concentration in Peru \\ Concentração do mercado de auditoria no Peru
}

Gerardo Gómez ${ }^{a}$

Universidad Nacional de Piura, Perú

DOI: https://doi.org/10.11144/Javeriana.cc22.cmap

lgomezj@unp.edu.pe

ORCID: https://orcid.org/0000-0002-5082-9621

Recibido: $11 / 05 / 2021$

Jesús Enrique Sandoval Imán

Aceptado: 09/09/2021

Colegio de Contadores Públicos de Piura, Perú

Publicado: 31/12/2021

ORCID: https://orcid.org/0000-0001-9326-458X

\section{Heber Poma}

Universidad Nacional del Altiplano Puno, Perú

ORCID: https://orcid.org/0000-0003-4468-3184

\section{Resumen:}

El objetivo de la investigación es analizar la concentración del mercado de auditoría en Perú en el período 2014-2019. Se construyó una data con los honorarios pagados por las empresas auditadas que fueron obtenidos del Reporte sobre el cumplimiento del Código de Buen Gobierno Corporativo de las empresas que cotizan en la Bolsa de Valores de Lima. La muestra la constituyen 638 empresas de diferentes sectores económicos de Perú. Utilizando indicadores de concentración de mercado, segmentación por sectores económicos y segmentación por tamaño de la empresa auditada es posible mostrar que el mercado de auditoría está altamente concentrado y dominado por las big four, que existen barreras de entrada para que las pequeñas sociedades de auditoría puedan brindar sus servicios a las empresas auditadas de mayor tamaño, que las sociedades de auditoría que dominan el mercado están especializadas por sectores de la economía peruana. Se comprueba también que se han especializado por tamaño de la empresa auditada y que las firmas de auditoría son eficientes en costos para poder atender de manera permanente a los diferentes segmentos de empresas auditadas.

Códigos JEL: L13, M41, M42.

Palabras clave: Mercado de auditoría, concentración de mercado, especialización, Perú.

\begin{abstract}
:
The objective of the research is to analyze the concentration of the auditing market in Peru in the period 2014-2019. A data was built with the fees paid by the audited companies that were obtained from the Report on compliance with the Code of Good Corporate Governance of companies listed on the Lima Stock Exchange. The sample is made up of 638 companies from different economic sectors in Peru. Using market concentration indicators, segmentation by economic sectors and segmentation by size of the audited company, it is possible to show that the auditing market is highly concentrated and dominated by the big four; that there are barriers to entry for small audit firms to provide their services to larger audited firms; that the audit firms are specialized by sector of the Peruvian economy. It is also verified that they have specialized by size of the audited company; and that audit firms are cost-efficient to be able to permanently serve the different segments of audited companies.
\end{abstract}

JEL Codes: L13, M41, M42.

Keywords: Auditing market, market concentration, specialization, Peru.

\section{Resumo:}

O objetivo da pesquisa é analisar a concentração do mercado de auditoria no Peru no período 2014-2019. Foi construído um dado com os honorários pagos pelas empresas auditadas, obtidos a partir do Relatório sobre o cumprimento do Código de Boa Governança Corporativa das empresas listadas na Bolsa de Valores de Lima. A amostra é composta por 638 empresas de diversos setores econômicos do Peru. Utilizando indicadores de concentração de mercado, segmentação por setores econômicos e segmentação por porte da empresa auditada, é possível evidenciar que o mercado de auditoria é altamente concentrado e dominado

Notas de autor

\footnotetext{
a Autor de correspondencia. E-mail: lgomezj@unp.edu.pe
} 
pelas big four, que existem barreiras de entrada para pequenas firmas de auditoria prestarem seus serviços a firmas maiores auditadas, que as firmas de auditoria são especializadas por setor da economia peruana. Verifica-se também que se especializaram por porte da empresa auditada e que as firmas de auditoria são eficientes em termos de custos para poder atender permanentemente os diferentes segmentos das empresas auditadas.

Códigos JEL: L13, M41, M42.

Palavras-chave: Mercado de auditoria, concentração de mercado, especialização, Peru.

\section{Introducción}

El mercado de auditoría en Perú no es ajeno a la dinámica internacional en la cual opera un grupo de firmas auditoras, las big four ${ }^{1}$ que concentran dicho mercado, y el resto de compañías con menores posibilidades de acceso a este mercado. Ruiz, Rodríguez \& Biedma (2016) manifiestan que existe evidencia empírica que confirma que el mercado de auditoría, sobre todo el de las empresas cotizadas, muestra elevados niveles de concentración. Esta característica puede influir en los honorarios a pagar a las firmas de auditoría (Eshleman \& Lawson, 2017) y en la calidad de la auditoría (Xu, 2017).

Para Gómez-Guillamón (2001) un análisis del mercado de auditoría es importante tanto por razones económicas como sociales; económicas porque al tratarse de un servicio prestado por la iniciativa privada debe perseguir siempre la maximización del beneficio derivada del ejercicio de su actividad, y sociales respecto a los beneficios derivados de la fiabilidad que aporta el análisis en un mercado como el de la auditoría a la información financiera.

En Perú las empresas cotizadas son supervisadas por la Superintendencia del Mercado de Valores (SMV) y están obligadas a presentar información financiera auditada al finalizar cada año. Por lo que el mercado de auditoría se centra principalmente en las empresas cotizadas, es por ello que este trabajo tiene como objetivo analizar la concentración de mercado de auditoría en Perú, teniendo como campo de estudio los servicios de auditoría que se brindan a las empresas que cotiza en la Bolsa de Valores de Lima (BVL).

En literatura existe una buena cantidad de investigaciones sobre el mercado de auditoría, sin embargo, no hay estudios para el caso peruano que analicen y permitan conocer el nivel de concentración del mercado, la competencia de los servicios de auditoría brindados por sectores económicos. Esta investigación es una primera aproximación al estudio del mercado de auditoría en Perú.

Toscano \& García (2011) manifiestan que es importante un análisis del mercado de la auditoría porque permite evidenciar y evaluar las estrategias con las que cuentan las sociedades de auditoría, además se tendrá conocimiento de la estructura del mercado. Por otra parte, Grigorescu (2014) manifiesta que un análisis de mercado de la auditoría permite la comparación entre otros mercados de distintos países con diferentes normas que los regulan. De igual manera, pone énfasis en la importancia de este análisis cuando expresa que el mercado de la auditoría posee diversas variables que han de ser analizadas tanto por la parte de la oferta, compuesta por las sociedades de auditoría; y la demanda, en estos casos las empresas que requieren sus estados financieros para fines de presentación.

Los estados financieros de las grandes empresas que hoy en día mueven la economía de un país y que cotizan en los mercados bursátiles se constituyen en instrumentos de análisis de las empresas, los cuales deben ser avalados y respaldados por sociedades de auditoría que cuenten con los estándares de calidad para poder prestar dicho servicio. Esta situación pone de manifiesto la necesidad de un análisis del mercado de la auditoría, puesto que son las empresas auditoras las que tienen la responsabilidad de emitir una opinión con base en el trabajo selectivo y objetivo que prima en estos casos y que se refleja en el dictamen que emiten.

La revisión de la literatura en el estudio de la concentración de mercado de los servicios de auditoría en Perú muestra que es un tema que no ha sido desarrollado, por lo que esta investigación constituye una primera aproximación al entendimiento de esta realidad, cubriendo un vacío en el conocimiento. 


\section{Revisión de la literatura}

\section{Concentración de mercado de auditoría}

La concentración de mercado de auditoría es el control monopolístico que ejercen un escaso número de firmas dentro de la industria de la auditoría respecto a otras sociedades. El dominio se mantiene con el paso del tiempo y se expresa en el poder de mercado que el reducido número de firmas posee al momento de pactar el precio del servicio de auditoría.

Beattie \& Fearnley (1994) encontraron que el mercado de auditoría en el Reino Unido presentó un alto nivel de concentración en las empresas que brindan estos servicios entre los años 1987 a 1991. Cuesta (2015) demostró la existencia de un alto nivel de concentración dentro del mercado de auditoría de España durante el periodo 1999-2009, en favor de las big four, consideradas por ser empresas con un alto prestigio en la prestación de los servicios alrededor del mundo, siendo este el factor principal para que estas empresas obtengan altas cuotas de mercado.

Toscano \& García (2011), con información de las empresas que cotizan en la Bolsa de Valores de México evidenciaron un alto nivel de concentración en el mercado de auditoría mexicano por parte de las bigfour durante el período 2001-2005. Por otra parte, Wolk, Michelson \& Wootton (2001) demostraron que entre los años 1988 y 1999 el mercado de auditoría de Estados Unidos presentó un fuerte dominio por parte de grandes firmas de auditoría dando como resultado la presencia de un alto nivel de concentración, que inicialmente fueron las big eight y luego de diversas fusiones de estas firmas el número de compañías se redujo a big six ${ }^{2}$.

Ruiz, Rodríguez, \& Biedma (2016) realizaron un estudio sobre el mercado de la auditoría en España para determinar la dinámica de la competencia y analizar la relación entre el nivel de concentración y las barreras de entrada con la competitividad de ese mercado en el período 2002-2010. Los autores demostraron la existencia de intensidad de competencia entre las firmas de auditoría en un mercado pequeño y con elevada concentración entre las firmas de auditoría, y además, que las barreras de entrada ejercen una influencia negativa en la competitividad. Ballas \& Fafaliou (2008) analizaron los cambios en los niveles de concentración del mercado de auditoría en 15 países miembros de la Unión Europea con una muestra de 2.862 clientes de firmas de auditoría para el período 1998-2004. Los resultados demuestran que, si bien los niveles de concentración varían en cada país, en el agregado los niveles de concentración aumentaron a lo largo del período de análisis.

Beattie, Goodacre \& Fearnley (2003) estudiaron las causas y consecuencias de la concentración del mercado de auditoría en Reino Unido con una muestra compuesta por 2.180 compañías que cotizaban en el mercado de capitales de Londres a abril de 2002. Los autores encontraron que las cuatro firmas más grandes de auditoría mantienen una cuota de mercado del $96 \%$; y que una sola firma auditora mantiene más del 70 $\%$ de cuota de mercado de seis de 38 sectores industriales. Buijink, Maijoor \& Meuwissen (1998) estudiaron las características del mercado de auditoría de Alemania y Holanda, en los años 1970 a 1994 y se tomó como muestra el número de auditores que aparecían en las listas de 16 firmas auditoras; los resultados demostraron que el mercado de auditoría de Holanda es más concentrado que el alemán.

Carson, Redmayne \& Liao (2014) analizaron la estructura del mercado de auditoría en Australia con una muestra de 1.858 empresas que cotizan en el mercado de valores para el período 2000-2011. Encontraron alta concentración del mercado con dos características definidas: las firmas de auditoría están altamente segmentadas en sectores económicos y tienen una alta concentración en proveer otros servicios adicionales a la auditoría de estados financieros. Guimarães \& Dantas (2015) estudiaron la concentración del mercado de auditoría en el sector bancario de Brasil con 182 conglomerados financieros e instituciones bancarias brasileñas para el período 2000-2014. Los resultados demuestran que el mercado de la auditoría para el sector 
financiero está altamente concentrado. Dicha concentración se sitúo en $86 \%$ del mercado dominado por KPMG y PWC.

Johnson, Walker \& Westergaard (1995) estudiaron el mercado de auditoría de Nueva Zelanda con en una muestra de 259 empresas registradas en el Departamento de Justicia en 1989. Los autores encontraron que las cinco firmas más grandes de auditoría dominan el mercado de auditoría; el cual está dividido en cuatro segmentos según el tamaño de las empresas auditadas. Martínez, Caso \& Río (2005) analizaron la concentración del mercado de auditoría en España en el período 1993-2002 con una muestra de 187 empresas que cotizan en la Bolsa de Valores de Madrid; encontrando que el mercado de auditoría en España estaba dominado por las grandes firmas multinacionales, las cuales acapararon entre el 92,7 \% y el 94,9\% del número de clientes auditados.

Peel (1997) estudió el mercado de auditoría del Reino Unido con una muestra de 171.799 grandes empresas auditadas del año 1996 y los principales hallazgos fueron: el tamaño de las corporaciones determina el nivel de concentración del mercado, la cuota de mercado aumentó de 72,3 \% en 1991 a 78,4 \% entre 1994 y 1995, y las seis firmas más grandes de auditoría abarcaban el 58,2 \% de las compañías de dicho mercado. De la misma manera, Pong (1999) analizó el mercado de auditoría inglés en años 1991 a 1995 con 1.401 compañías y demostró que las cuatro grandes firmas de auditoría mantenían el 60 \% del total de auditorías y obtenían el $79 \%$ del total de los honorarios pagados en este mercado. El autor concluyó que este mercado se configura en un oligopolio debido a que existen poco ofertantes del servicio de auditoría y muchos demandantes de tales servicios.

Wolk, Michelson \& Wootton (2001) estudiaron el mercado de auditoría de los Estados Unidos en el período 1988-1999, analizaron las empresas cotizadas en la New York Stock Exchange (NYSE), en la American Stock Exchange (AMEX) y en la National Association of Securities Dealers (NASDAQ). Los resultados mostraron que el nivel de concentración en el mercado de auditoría fue incrementándose a lo largo del período de análisis

\section{Características de la concentración del mercado de auditoría}

Los estudios en este campo identifican como característica común una elevada concentración dominada por las bigfour que obtienen cuotas de mercado muy altas (Beattie \& Fearnley, 1994; Cuesta, 2015; Toscano \& García, 2011; Wolk, Michelson \& Wootton, 2001; Ballas \& Fafaliou, 2008; Carson, Redmayne \& Liao, 2014; Guimarães \& Dantas, 2015; Johnson, Walker \& Westergaard, 1995). Estos resultados llegan a demostrar que el mercado de auditoría es oligopólico. Esta estructura de mercado distorsiona el funcionamiento del mismo debido a que genera elevadas rentabilidades, precios altos, barreras de entrada y disminución de la competencia entre las empresas.

En las estructuras de mercado monopolísticas pocas empresas mantienen una cuota elevada, generan barreras de entrada para nuevos competidores y los líderes pueden incurrir en conductas anticompetitivas buscando maximizar los beneficios, todo lo cual causa distorsiones en el funcionamiento del mercado (Ruiz et al., 2016). De la misma manera, Sellers \& Más Ruiz (2008) señalan que el mercado concentrado de auditoría tiene efectos positivos en la rentabilidad como consecuencia de mayores cuotas, generando así mayores beneficios a las empresas que tienen el control de una determinada industria.

Una consecuencia de la concentración es el aumento de los precios que cobran las firmas de auditoría, relacionado con la escasa competencia. En un mercado altamente concentrado las tarifas por los servicios tienden a aumentar a lo largo del tiempo (Asthana, Khurana \& Raman, 2019; Bhattacharya, \& Banerjee, 2020; Eshleman \& Lawson, 2017; Eshleman, Ke \& Li, 2018; Huang, Chang \& Chiou, 2016; Johnson, Walker \& Westergaard, 1995; Simunic, 1980; Van Caneghem, 2010). Al respecto, Ruíz \& Rodríguez (2013) manifiestan que el análisis de mercado de la auditoría revela que debido al poder de mercado que tienen los 
ofertantes del servicio pueden establecer elevados precios a sus clientes, un servicio que a veces los clientes están dispuestos aceptar con tal de recibirlo y tener la plena seguridad que la información revelada no presenta errores que puedan distorsionar el mercado.

Si el mercado de auditoría es competitivo en cuanto a precios, las firmas auditoras generalmente serán disciplinadas por las fuerzas del mercado para realizar auditorías eficientes y tendrán poca capacidad de obtener ganancias excesivas de sus clientes (Ciconte, Knechel \& Schelleman, 2015). Para que el mercado de auditoría sea competitivo en precios tiene que haber una competencia intensiva entre el reducido número de firmas auditoras del mercado; y esta competencia se tiene que orientar a la eficiencia en el servicio brindado y en las economías de escala que normalmente lo tienen las grandes empresas.

Otra consecuencia de la concentración del mercado de auditoría es la especialización en sectores económicos de las empresas auditadas. Así lo demuestran los trabajos de Scott \& Gist (2013), Eichenseher \& Danos (1981), Hogan \& Jeter (1999), Craswell, Francis \& Taylor (1995), Carson \& Fargher (2007), Abidin, Beattie \& Goodacre (2010), Francis, Reichelt \& Wang (2005). La especialización en el mercado de auditoría es parte de los esfuerzos de estas firmas por buscar diferenciación, y con ello se puede inferir que existe una competencia intensa en este mercado. Hay \& Jeter (2011) manifiestan que las firmas auditoras se orientan a la especialización de la industria para diferenciarse de sus competidores proporcionando un servicio de mayor calidad, que mejore la reputación de la firma auditora con la intención de lograr mayores ganancias a través de precios más elevados por el servicio brindado.

Guiral \& Gonzalo (2005) manifiestan que existe un efecto positivo para la empresa al momento de hacer un análisis del mercado de auditoría, el cual tiene como referencia el informe de auditoría, ya que, son los auditores quienes dictaminan si una empresa presenta razonablemente la información financiera. Lopes (2013) manifiesta que el análisis del mercado de la auditoría acarrea un efecto vital para el mercado de valores porque por medio de la emisión de un dictamen de auditoría se brinda transparencia y calidad de la información financiera de una empresa, permitiendo así evaluar la eficiencia de los mercados de capitales. La verificación de la eficiencia de la información auditada depende únicamente de la rapidez con que los precios reaccionen a la información publicada y no con el hecho que los precios reflejen la toda la información pública en el mercado de acuerdo con la teoría de mercados eficientes.

\section{Hipótesis}

De la literatura revisada se plantearon cuatro hipótesis que se relacionan a continuación. $\mathrm{H}_{1}$ : El mercado de auditoría en Perú está altamente concentrado. $\mathrm{H}_{2}$ : Las firmas de auditoría están especializadas por sector de la actividad de la empresa auditada. $\mathrm{H}_{3}$ : Las sociedades de auditoría se especializan por tamaño de actividad de las empresas auditadas. $\mathrm{H}_{4}$ : Las sociedades de auditoría trabajan con economías de escala.

\section{Metodología}

La investigación realizada es de tipo descriptiva, con un enfoque cuantitativo. Para analizar la concentración de mercado de los servicios de auditoría ofertados en el Perú se utilizaron dos medidas: el Índice de Concentración de Orden $n$ (ICn) y el Índice de Herfindahl-Hirschman (HHI).

El Índice de Concentración de Orden $n$ (ICn) es una medida discreta de concentración que mide la suma de las participaciones de las n mayores empresas en relación con el total del mercado. Ver ecuación 1. 


\section{$I C n=\frac{\sum_{1}^{n} F n}{F}$}

Donde $\mathrm{F} n$ representa los ingresos por honorarios de auditoría de las n empresas más grandes (big four). F representa la facturación del total de mercado en términos de honorarios cobrados por las firmas que participan en el mercado. Zurita (2014) manifiesta que este índice tiene como principal ventaja su sencillez, interpretación inmediata y facilidad de cálculo. La desventaja radica en que al no considerar a todas las empresas que participan en el mercado no puede detectar cambios estructurales del mercado.

El Índice de Herfindahl-Hirschman (HHI) mide el nivel de concentración de la totalidad del mercado tomando en cuenta a todas las empresas que participan en dicha industria. Es la suma de los cuadrados de las cuotas de mercado de cada una de las empresas que participan en él. La principal ventaja de este indicador es que combina información entre el número de firmas y la distribución del tamaño de las mismas, haciendo que un mayor HHI represente un mayor nivel de concentración de mercado. Toma en consideración el número total de empresas de la industria y da un mayor peso a las compañías con mayor participación en un mercado. La principal desventaja del HHI es que no toma en cuenta las complejidades de los mercados, y por ende no permite hacer evaluaciones más precisas de las condiciones competitivas o de monopolio de un mercado. Ver ecuación 2.

$$
H H I=\sum_{i=1}^{N} Z i^{2}
$$

Donde, $\mathrm{Zi}$ es la cuota de la i-ésima firma auditora que participa en el mercado. $\mathrm{N}$ representa el número de firmas activas en el mercado. Si HHI $=10.000$ significa que el mercado es un monopolio; si $\mathrm{HHI}<100$ el mercado es muy competitivo; si $100<\mathrm{HHI}<1.500$ el mercado esta desconcentrado; si $1.500<\mathrm{HHI}<2.500$ el mercado está concentrado; y si HHI > 2.500 el mercado está altamente concentrado. Toscano \& García (2011) manifiestan que el HHI como indicador de concentración del mercado de auditoría se orienta a que las pequeñas empresas auditoras ejercen una menor influencia sobre los resultados del cálculo del índice con respecto a la influencia de las grandes firmas.

\section{Muestra}

La muestra está constituida por 638 empresas financieras y no financieras de Perú que cotizan en la Bolsa de Valores de Lima (BVL) y que divulgaron el honorario cancelado por el servicio de auditoría en el período 2014-2019. Esta información fue obtenida del Reporte sobre el cumplimiento del Código de Buen Gobierno Corporativo. En el período de estudio se encontró el mayor número de empresas que divulgaron el honorario pagado a la firma auditora. El honorario se constituye en información fundamental para estudiar la estructura de mercado de auditoría (Ruiz et al., 2016). Las sociedades de auditoría que forman parte del estudio son las bigfour: KPMG, Deloitte Touche Tohmatsu Limited (DTT), Price Waterhouse Cooper (PWC) y Ernst \& Young (EY), y un conjunto 26 firmas de auditoría que se denomina Otras. 
TABLA 1

Distribución de la muestra

\begin{tabular}{|c|c|c|}
\hline \multicolumn{3}{|c|}{ Panel A: Distribución anual de las empresas auditadas y firmas de auditoría } \\
\hline Años & $\begin{array}{c}\mathrm{N}^{\circ} \text { empresas } \\
\text { auditadas }\end{array}$ & $\begin{array}{c}\mathrm{N}^{\circ} \text { firmas de } \\
\text { auditoría }\end{array}$ \\
\hline 2014 & 112 & 18 \\
\hline 2015 & 116 & 18 \\
\hline 2016 & 115 & 16 \\
\hline 2017 & 113 & 19 \\
\hline 2018 & 102 & 17 \\
\hline 2019 & 80 & 15 \\
\hline Total & 638 & \\
\hline \multicolumn{3}{|c|}{ Panel B: Distribución sectorial de las sociedades auditadas } \\
\hline Sector & $\begin{array}{c}\mathrm{N}^{\circ} \text { empresas } \\
\text { auditadas }\end{array}$ & $\begin{array}{l}\mathrm{N}^{\circ} \text { máximo de firmas de } \\
\text { auditoría por sector }\end{array}$ \\
\hline Fondo de pensiones & 17 & 04 \\
\hline Agrario & 59 & 07 \\
\hline Bancos y financieras & 138 & 09 \\
\hline Diversas & 153 & 12 \\
\hline Industriales & 79 & 08 \\
\hline Mineras & 63 & 07 \\
\hline Seguros & 62 & 05 \\
\hline Servicios públicos & 67 & 07 \\
\hline Total & 638 & $19^{*}$ \\
\hline \multicolumn{3}{|c|}{$\begin{array}{l}\text { El total de empresas de auditoria, no se corresponde con la suma del número de } \\
\text { empresas de cada sector, debido a que una misma firma puede prestar sus servicios en } \\
\text { más de un sector. }\end{array}$} \\
\hline
\end{tabular}

La tabla 1, panel A presenta la muestra de estudio compuesta por 638 empresas que han divulgado honorarios pagados a las firmas auditoras. En cuanto al número de empresas auditadas estas aumentan en 2015, para luego comenzar a disminuir en los últimos años, en 2014 fueron 112 empresas auditadas, mientras que en 2019 hubo 80 empresas. El número de firmas de auditoría fue variable a lo largo del período del estudio, en 2014 hubo 18 empresas que realizaron auditoría a 112 empresas, mientras que en 2019 fueron 15 firmas auditoras que realizaron su trabajo en 81 empresas. Por otra parte, el panel B muestra la distribución por sectores económicos establecidos por la BVL, así como el número de firmas de auditoría máximas por cada sector. El sector Diversas fue el que generó el mayor número de empresas auditadas, seguido de los sectores Bancos y Financieras e Industriales. En cuanto al número máximo de firmas de auditoría se puede observar que para los sectores Diversas y Bancos y Financieras hubo 12 y 9 sociedades de auditoría respectivamente. Esto lleva a establecer que las sociedades de auditoría están especializadas en empresas financieras y del sector diversas.

\section{Resultados}

TABLA 2

Cuota de mercado y posición en el ranking de las firmas de auditoría

\begin{tabular}{|c|c|c|c|c|c|}
\hline Años & $\begin{array}{c}\text { PWC } \\
(\%)\end{array}$ & $\begin{array}{c}\text { EY } \\
(\%)\end{array}$ & $\begin{array}{c}\text { DTT } \\
(\%)\end{array}$ & $\begin{array}{c}\text { KPMG } \\
(\%)\end{array}$ & $\begin{array}{c}\text { OTRAS } \\
(\%)\end{array}$ \\
\hline 2014 & $35,48(2)$ & $43,16(1)$ & $13,52(3)$ & $4,56(4)$ & $3,28(5)$ \\
\hline 2015 & $49,09(1)$ & $33,20(2)$ & $8,82(3)$ & $5,74(4)$ & $3,14(5)$ \\
\hline 2016 & $50,18(1)$ & $33,80(2)$ & $8,17(3)$ & $5,25(4)$ & $2,60(5)$ \\
\hline 2017 & $39,66(1)$ & $30,50(2)$ & $2,72(5)$ & $12,46(4)$ & $14,66(3)$ \\
\hline 2018 & $40,55(1)$ & $18,23(4)$ & $2,01(5)$ & $18,84(3)$ & $20,37(2)$ \\
\hline 2019 & $37,40(1)$ & $22,27(3)$ & $2,11(5)$ & $25,50(2)$ & $12,72(4)$ \\
\hline
\end{tabular}

Fuente: elaboración propia. 
La tabla 2 muestra la cuota de mercado y el ranking de las sociedades de auditoría en el mercado peruano con base en los honorarios percibidos. Tal como la literatura lo manifiesta, las bigfour dominan el mercado peruano. En 2014, EY ocupa la primera posición con una cuota de mercado del 43 \%, seguida de PWC con una cuota del $35 \%$. Un poco más alejados queda DTT y KPMG con una cuota de $14 \%$ y $5 \%$ respectivamente, ocupando las posiciones 3 y 4 . A partir del 2015 hasta el 2019, PWC ha dominado el mercado, llegando a tener una cuota del $50 \%$ en 2016, y un $37 \%$ de participación en 2019. Por otra parte, el segundo lugar lo obtuvo EY en los años 2015 al 2017 con una cuota de mercado que fluctuó entre el $31 \%$ y el $34 \%$ de participación. Para los años 2018 y 2019, EY retrocedió al cuarto lugar y tercer lugar respectivamente. DTT, en 2014 tuvo una cuota de mercado del $14 \%$ ocupando la tercera posición, pero a partir de allí, su participación en el mercado fue disminuyendo, hasta tener una participación del $2 \%$ en los años 2018 y 2019; en el período 2017-2019 pasó a ocupar el quinto lugar del ranking. KPMG ha tenido una participación mucho más ventajosa en el mercado; en 2014 tenía una cuota del 5 \% y ocupaba la cuarta posición, pero en 2019 tuvo una participación del $26 \%$, ocupando la segunda posición.

Las Otras firmas, en los años 2018 y 2019 lograron capturar una cuota de mercado del $20 \%$ y $13 \%$ respectivamente, llegando a ocupar el segundo lugar del ranking en 2018. Estas cifras permiten inferir que, si bien el mercado de auditoría peruano está dominado por las big four, el mercado tiene una intensidad competitiva entre las mismas. Hay competencia para poder obtener una mayor cuota de mercado, y ello hace que se generen beneficios en las empresas auditadas, entre ellos el precio del servicio.

TABLA 3

Índice de concentración de orden n del mercado de auditoría

\begin{tabular}{|c|c|c|c|c|c|c|}
\hline ICn & $\mathbf{2 0 1 4}$ & $\mathbf{2 0 1 5}$ & $\mathbf{2 0 1 6}$ & $\mathbf{2 0 1 7}$ & $\mathbf{2 0 1 8}$ & $\mathbf{2 0 1 9}$ \\
\hline $\mathrm{C}_{1}$ & $43 \%$ & $49 \%$ & $50 \%$ & $40 \%$ & $41 \%$ & $37 \%$ \\
\hline $\mathrm{C}_{2}$ & $79 \%$ & $82 \%$ & $84 \%$ & $70 \%$ & $59 \%$ & $63 \%$ \\
\hline $\mathrm{C}_{3}$ & $92 \%$ & $91 \%$ & $92 \%$ & $83 \%$ & $78 \%$ & $85 \%$ \\
\hline $\mathrm{C}_{4}$ & $97 \%$ & $97 \%$ & $97 \%$ & $85 \%$ & $80 \%$ & $87 \%$ \\
\hline
\end{tabular}

Fuente: elaboración propia.

Los indicadores de concentración han sido utilizados por la literatura para poder aproximarse a comprender las características estructurales del mercado, son utilizados para poder explicar el nivel de competencia de una industria como consecuencia de la estructura de mercado (Zurita, 2014). La tabla 3 muestra los resultados del ICn del mercado de auditoría con base en los honorarios percibidos por las big four. Se puede afirmar que para el período 2014-2016 las cuatro firmas internacionales dominaron el mercado peruano, al presentar $97 \%$ de concentración. Para el período 2017-2019, los niveles de concentración fluctuaron entre el $80 \%$ y el $87 \%$. Si bien hay una disminución del nivel de concentración, con respecto al período anterior, este mercado es dominado por cuatro firmas auditoras.

TABLA 4

Índice de Herfindahl-Hirschman del mercado de auditoría

\begin{tabular}{|l|c|c|c|c|c|c|}
\hline Años & $\mathbf{2 0 1 4}$ & $\mathbf{2 0 1 5}$ & $\mathbf{2 0 1 6}$ & $\mathbf{2 0 1 7}$ & $\mathbf{2 0 1 8}$ & $\mathbf{2 0 1 9}$ \\
\hline Índice HHI & 3.326 & 3.623 & 3.754 & 2.666 & 2.335 & 2.550 \\
\hline
\end{tabular}

Fuente: elaboración propia.

La tabla 4 presenta los resultados del HHI para el mercado de auditoría de las big four en Perú. Estos datos confirman que el mercado de auditoría está altamente concentrado ( HHI > 2500), excepto para 2018, donde el nivel de concentración disminuye a la categoría de concentrado $(1500<\mathrm{HHI}<2500)$. Se demuestra que este mercado está fuertemente dominado por las bigfour; y que tiene intensidad competitiva entre los cuatro grandes por captar una mayor cuota de mercado. Igualmente se confirma que el mercado es oligopolista, tal 
como lo demostraron Toscano \& García (2011) para el mercado de auditoría de México. Este análisis permite concluir que la hipótesis primera queda aceptada.

Los resultados mostrados en las tablas 2, 3 y 4 permiten establecer que este fuerte dominio de las bigfour en el mercado de auditoría peruana conlleva a la generación de barreras de entrada a este sector, y desestimula la creación de nuevas firmas para competir en este mercado.

TABLA 5

Participación por sectores de las sociedades de auditoría en el mercado de auditoría peruano

\begin{tabular}{|c|c|c|c|c|c|c|c|c|c|c|c|c|}
\hline \multirow{3}{*}{$\begin{array}{l}\text { Sectores } \\
\text { económicos }\end{array}$} & \multicolumn{2}{|c|}{2014} & \multicolumn{2}{|c|}{2015} & \multicolumn{2}{|c|}{2016} & \multicolumn{2}{|c|}{2017} & \multicolumn{2}{|c|}{2018} & \multicolumn{2}{|c|}{2019} \\
\hline & \multicolumn{12}{|c|}{ Porcentaje de empresas auditadas por } \\
\hline & $\begin{array}{c}\text { Big } \\
\text { four }\end{array}$ & Otras & $\begin{array}{l}\text { Big } \\
\text { four }\end{array}$ & Otras & $\begin{array}{c}\text { Big } \\
\text { four }\end{array}$ & Otras & $\begin{array}{c}\text { Big } \\
\text { four }\end{array}$ & Otras & $\begin{array}{c}\text { Big } \\
\text { four }\end{array}$ & Otras & $\begin{array}{c}\text { Big } \\
\text { four }\end{array}$ & Otras \\
\hline $\begin{array}{l}\text { Fondo de } \\
\text { pensiones }\end{array}$ & 100 & 0 & 100 & 0 & 100 & 0 & 100 & 0 & 100 & 0 & 100 & 0 \\
\hline Agrario & 82 & 18 & 82 & 18 & 82 & 18 & 73 & 27 & 67 & 33 & 67 & 33 \\
\hline $\begin{array}{l}\text { Bancos y } \\
\text { financieras }\end{array}$ & 88 & 12 & 89 & 11 & 88 & 12 & 88 & 12 & 96 & 4 & 94 & 6 \\
\hline Diversas & 85 & 15 & 83 & 17 & 82 & 18 & 79 & 21 & 79 & 21 & 82 & 18 \\
\hline Industriales & 85 & 15 & 79 & 21 & 79 & 21 & 77 & 23 & 77 & 23 & 75 & 25 \\
\hline Mineras & 80 & 20 & 73 & 27 & 73 & 27 & 73 & 27 & 80 & 20 & 80 & 20 \\
\hline Seguros & 100 & 0 & 91 & 9 & 91 & 9 & 91 & 9 & 90 & 10 & 100 & 0 \\
\hline $\begin{array}{l}\text { Servicios } \\
\text { publicos }\end{array}$ & 85 & 15 & 100 & 0 & 100 & 0 & 100 & 0 & 64 & 36 & 100 & 0 \\
\hline
\end{tabular}

Fuente: elaboración propia.

La especialización en sectores económicos es una consecuencia de la competencia que se genera en un mercado orientado a la estrategia de la diferenciación. Las sociedades de auditoría buscan especializarse para poder obtener ventajas competitivas que les permitan hacerse fuertes en un nicho específico de mercado y con ello limitar la competencia en dicho sector. La tabla 5 muestra la participación de las bigfour y las Otras sociedades de auditoría en cada sector económico donde están clasificadas las empresas auditadas. Como se puede comprobar, las cuatro grandes tienen una fuerte participación en todos los sectores económicos con respecto a las Otras firmas. En el sector Fondo de Pensiones solo han realizado el servicio de auditoría las cuatro grandes firmas. Igualmente ocurre en el sector Seguros para los años 2014 y 2019 y en el sector Servicios Públicos para los años 2015, 2016, 2017 y 2019. Los resultados demuestran que las grandes sociedades de auditoría se encuentran especializadas en todos los sectores económicos en Perú, esto lleva a inferir que existe intensidad competitiva entre las bigfour debido a la alta concentración.

TABLA 6

Nivel de concentración por sectores económicos

\begin{tabular}{|c|c|c|c|c|c|c|c|c|c|c|c|c|}
\hline \multirow[b]{2}{*}{$\begin{array}{l}\text { Sectores } \\
\text { económicos }\end{array}$} & \multicolumn{2}{|c|}{2014} & \multicolumn{2}{|c|}{2015} & \multicolumn{2}{|c|}{2016} & \multicolumn{2}{|c|}{2017} & \multicolumn{2}{|c|}{2018} & \multicolumn{2}{|c|}{2019} \\
\hline & $\begin{array}{l}\mathrm{N}^{\circ} \mathrm{de} \\
\text { firmas }\end{array}$ & HHI & $\begin{array}{l}N^{\circ} \text { de } \\
\text { firmas }\end{array}$ & HHI & $\begin{array}{l}\mathrm{N}^{\circ} \mathrm{de} \\
\text { firmas }\end{array}$ & HHI & $\begin{array}{l}\mathrm{N}^{\circ} \mathrm{de} \\
\text { firmas }\end{array}$ & HHI & $\begin{array}{l}\mathrm{N}^{\circ} \mathrm{de} \\
\text { firmas }\end{array}$ & HHI & $\begin{array}{l}\mathrm{N}^{\circ} \mathrm{de} \\
\text { firmas }\end{array}$ & HHI \\
\hline $\begin{array}{l}\text { Fondo de } \\
\text { pensiones }\end{array}$ & 03 & 4.494 & 03 & 3.471 & 02 & 4.022 & 03 & 3.677 & 03 & 3.654 & 02 & 5.479 \\
\hline Agrario & 05 & 1.858 & 05 & 1.554 & 05 & 1.494 & 06 & 1.951 & 06 & 4.492 & 04 & 3.227 \\
\hline $\begin{array}{l}\text { Bancos y } \\
\text { financieras }\end{array}$ & 07 & 1.733 & 07 & 1.263 & 06 & 1.292 & 06 & 1.486 & 05 & 1.703 & 05 & 2.740 \\
\hline Diversas & 08 & 5.096 & 09 & 4.971 & 08 & 5.366 & 09 & 2.773 & 08 & 3.011 & 06 & 3.778 \\
\hline Industriales & 04 & 1.998 & 05 & 1.861 & 04 & 2.878 & 04 & 3.183 & 05 & 2.948 & 05 & 1.460 \\
\hline Mineras & 06 & 2.566 & 07 & 2.958 & 06 & 3.020 & 06 & 2.611 & 05 & 3.344 & 05 & 3.190 \\
\hline Seguros & 04 & 1.306 & 04 & 1.161 & 05 & 1.055 & 05 & 1.095 & 04 & 1.410 & 03 & 1.427 \\
\hline $\begin{array}{l}\text { Servicios } \\
\text { públicos }\end{array}$ & 05 & 1.366 & 04 & 1.496 & 04 & 2.051 & 03 & 1.472 & 04 & 1.530 & 03 & 1.862 \\
\hline Total & 18 & 3.326 & 18 & 3.623 & 16 & 3.754 & 19 & 2.666 & 17 & 2.335 & 15 & 2.550 \\
\hline
\end{tabular}

La tabla 6 muestra el nivel de concentración del mercado de auditoría de acuerdo con los sectores económicos establecidos por la BVL. El elevado nivel de concentración de mercado y la participación de pocas firmas determinan el nivel de especialización de un sector económico. Se puede observar que el sector Fondo de Pensiones está altamente concentrado (HHI > 2500) y solo es dominado por tres sociedades de auditoría. Esto demuestra que se necesita una especialización mucho más elevada que el resto de sectores debido a que el HHI está por encima del mercado total. Lo mismo ocurre con el sector Diversas, el cual es dominado por 
ocho firmas y el HHI del sector es mayor al HHI del mercado total. Otro sector altamente concentrado es el de las empresas mineras al estar dominado por seis sociedades de auditoría.

Los resultados mostrados en las tablas 5 y 6 llevan a reflexionar que la especialización en los diversos sectores de la economía peruana genera ventajas en el sentido que las empresas pueden contar con servicios de auditoría para atender las necesidades de transparencia de la información sin importar el sector donde se encuentren, esto hace que el mercado de auditoría sea atractivo tanto para las firmas auditoras como para las compañías auditada

TABLA 7

Participación de las sociedades de auditoría en sectores especializados

\begin{tabular}{|c|c|c|c|c|c|c|c|c|c|c|c|c|}
\hline \multirow{2}{*}{$\begin{array}{l}\text { Sector } \\
\text { económico }\end{array}$} & \multicolumn{2}{|c|}{2014} & \multicolumn{2}{|c|}{2015} & \multicolumn{2}{|c|}{2016} & \multicolumn{2}{|c|}{2017} & \multicolumn{2}{|c|}{2018} & \multicolumn{2}{|c|}{2019} \\
\hline & Firmas & $\begin{array}{l}\text { Cuota } \\
(\%)\end{array}$ & Firmas & $\begin{array}{l}\text { Cuota } \\
(\%)\end{array}$ & Firmas & $\begin{array}{l}\text { Cuota } \\
(\%)\end{array}$ & Firmas & $\begin{array}{c}\text { Cuota } \\
(\%)\end{array}$ & Firmas & $\begin{array}{c}\text { Cuota } \\
(\%)\end{array}$ & Firmas & $\begin{array}{l}\text { Cuota } \\
(\%)\end{array}$ \\
\hline \multirow{3}{*}{$\begin{array}{l}\text { Fondo de } \\
\text { Pensiones }\end{array}$} & KPMG & 38 & KPMG & 33 & KPMG & 48 & KPMG & 25 & KPMG & 25 & PWC & 65 \\
\hline & DTT & 7 & DTT & 25 & PWC & 52 & PWC & 48 & PWC & 48 & EY & 35 \\
\hline & EY & 55 & PWC & 42 & & & EY & 27 & EY & 27 & & \\
\hline \multirow{5}{*}{ Diversas } & KPMG & 2 & KPMG & 1 & KPMG & 1 & KPMG & 3 & KPMG & 4 & KPMG & 5 \\
\hline & PWC & 83 & PWC & 84 & PWC & 81 & PWC & 27 & PWC & 23 & PWC & 30 \\
\hline & DTT & 2 & DTT & 1 & DTT & 1 & EY & 21 & EY & 21 & EY & 7 \\
\hline & EY & 12 & EY & 13 & EY & 16 & OTRAS & 49 & OTRAS & 52 & OTRAS & 58 \\
\hline & OTRAS & 1 & OTRAS & 1 & OTRAS & 1 & & & & & & \\
\hline \multirow{5}{*}{ Mineras } & KPMG & 6 & KPMG & 2 & PWC & 15 & PWC & 18 & PWC & 28 & PWC & 26 \\
\hline & PWC & 17 & PWC & 10 & DTT & 1 & DTT & 1 & DTT & 6 & DTT & 9 \\
\hline & DTT & 1 & DTT & 1 & EY & 75 & EY & 70 & EY & 55 & EY & 54 \\
\hline & EY & 68 & EY & 76 & OTRAS & 9 & OTRAS & 11 & OTRAS & 11 & OTRAS & 11 \\
\hline & OTRAS & 8 & OTRAS & 11 & & & & & & & & \\
\hline
\end{tabular}

Fuente: elaboración propia.

La tabla 7 muestra la participación de las sociedades de auditoría en los sectores económicos que en la tabla 6 se definieron como especializados: Fondo de Pensiones, Diversas y Mineras. Se puede observar que PWC y EY son las firmas que están especializadas en los sectores Fondo de Pensiones y Diversas y en el sector Mineras respectivamente. El sector Fondo de Pensiones desde 2015 hasta 2019 estuvo dominado por PWC. En 2015 la cuota de mercado fue de $42 \%$ y para el 2019 esta cuota se sitúa en $65 \%$ con un dominio del sector de manera ascendente. En el sector Diversas, PWC igualmente está especializada, de 2014 a 2016 la cuota de mercado en este sector es bastante elevado, fluctúa entre el $81 \%$ y el $84 \%$. Si bien se puede observar que para el período 2017-2019 este sector es dominado por el rubro Otras sociedades, PWC sigue teniendo una cuota de mercado que tiene una variación entre el $23 \%$ y $30 \%$. En el sector Mineras, EY es la firma especializada, en 2014 la cuota de mercado era de $68 \%$ y en 2019 de $54 \%$ con un claro dominio del mercado en este sector. Las demás sociedades que conforman las bigfour no están especializadas en estos sectores, pero sí tienen algún tipo de participación. DTT participa en los sectores Fondo de Pensiones, Diversas y Mineras, pero no mantiene una presencia en todo el período de estudio. Por otra parte, KPMG tiene el mismo comportamiento, participa en todos los sectores, pero con una cuota de mercado más significativa en el sector Fondo de Pensiones en el período 2014-2018.

Los resultados presentados en las tablas 5, 6 y 7 muestran que la especialización en sectores económicos por parte de las sociedades de auditoría es una estrategia que permite ganar una mayor cuota de mercado y a la vez generar ventaja competitiva en un mercado claramente dominado por cuatro firmas. Con estos resultados se acepta la hipótesis segunda. 
TABLA 8

Participación de las sociedades de auditoría por tamaño de la empresa auditada

\begin{tabular}{|c|c|c|c|c|c|c|c|c|c|c|c|c|}
\hline \multirow{3}{*}{$\begin{array}{l}\text { Tamaño de la } \\
\text { empresa auditada } \\
\text { (millones de soles) }\end{array}$} & \multicolumn{2}{|c|}{2014} & \multicolumn{2}{|c|}{2015} & \multicolumn{2}{|c|}{2016} & \multicolumn{2}{|c|}{2017} & \multicolumn{2}{|c|}{2018} & \multicolumn{2}{|c|}{2019} \\
\hline & \multicolumn{12}{|c|}{ Porcentaje de empresas auditadas por } \\
\hline & $\begin{array}{l}\text { Big } \\
\text { four }\end{array}$ & Otras & $\begin{array}{l}\text { Big } \\
\text { four }\end{array}$ & Otras & $\begin{array}{c}\text { Big } \\
\text { four }\end{array}$ & Otras & $\begin{array}{c}\text { Big } \\
\text { four }\end{array}$ & Otras & $\begin{array}{c}\text { Big } \\
\text { four }\end{array}$ & Otras & $\begin{array}{c}\text { Big } \\
\text { four }\end{array}$ & Otras \\
\hline (1) Menos de 50 & 75 & 25 & 69 & 31 & 75 & 25 & 73 & 27 & 74 & 26 & 77 & 23 \\
\hline (2) De 50 a 250 & 89 & 11 & 89 & 11 & 79 & 21 & 71 & 29 & 65 & 35 & 71 & 29 \\
\hline (3) De 251 a 1000 & 92 & 8 & 95 & 5 & 95 & 5 & 93 & 7 & 89 & 11 & 96 & 4 \\
\hline (4) De 1001 a 2500 & 87 & 13 & 87 & 13 & 89 & 11 & 90 & 10 & 90 & 10 & 100 & - \\
\hline (5) De 2501 a 4000 & 100 & - & 100 & - & 100 & - & 100 & - & 100 & - & 100 & - \\
\hline (6) De 4001 a 6000 & 100 & - & 100 & - & 100 & - & 100 & - & 100 & - & 100 & - \\
\hline (7) Más de 6000 & 100 & - & 100 & - & 100 & - & 100 & - & 100 & - & 100 & - \\
\hline
\end{tabular}

En la tabla 8 se presenta información del tamaño de las empresas auditadas medidas en función de sus ingresos operacionales. Se dividió el tamaño en siete rangos. Por otra parte, se presenta la información del porcentaje de empresas que han sido auditadas por las big four o por las Otras sociedades. Es importante establecer si el tamaño de las empresas auditadas influye en la decisión de contratar los servicios de una sociedad auditora. Se puede observar que en todos los rangos las bigfour dominan el mercado, de la misma manera se puede observar que la participación de las Otras sociedades se hace más intensa en los rangos 1 y 2 , disminuyendo su participación en los rangos 3 y 4 para finalmente no tener participación en los rangos 5, 6 y 7 en donde se encuentran las empresas de mayor tamaño. Estos resultados muestran que en la medida que las empresas tengan un mayor tamaño contratan a una de las bigfour, lo que genera una mayor competencia entre estas firmas. Por otra parte, se demuestra que existen barreras de entrada al mercado para auditar a empresas de mayor tamaño por parte de las otras sociedades existentes en el mercado, debido a que estas sociedades solo logran realizar auditorías en las empresas de menor tamaño (rangos 1 y 2 ).

Los resultados de la tabla 8 muestran la realidad de las firmas auditoras pequeñas, que a pesar que compiten en el mercado con las cuatro grandes, no pueden acceder a auditar a empresas de gran tamaño. Esto lleva a establecer que dentro del mercado de auditoría existe una significativa desigualdad de oportunidades para brindar los servicios de auditoría en Perú. Las razones de ello quizá se deban a factores tecnológicos y a factores humanos que restan competitividad a las pequeñas firmas auditoras.

TABLA 9

Nivel de concentración del mercado de auditoría por tamaño de empresa auditada

\begin{tabular}{|c|c|c|c|c|c|c|c|c|c|c|c|c|}
\hline \multirow{2}{*}{$\begin{array}{l}\text { Tamaño de la } \\
\text { empresa auditada } \\
\text { (millones de soles) }\end{array}$} & \multicolumn{2}{|c|}{2014} & \multicolumn{2}{|c|}{2015} & \multicolumn{2}{|c|}{2016} & \multicolumn{2}{|c|}{2017} & \multicolumn{2}{|c|}{2018} & \multicolumn{2}{|c|}{2019} \\
\hline & $\begin{array}{l}N^{\circ} \text { de } \\
\text { firmas }\end{array}$ & HHI & $\begin{array}{l}\begin{array}{l}N^{\circ} \text { de } \\
\text { firmas }\end{array} \\
\text { a }\end{array}$ & HHI & $\begin{array}{l}N^{\circ} \text { de } \\
\text { firmas }\end{array}$ & HHI & $\begin{array}{l}N^{\circ} \text { de } \\
\text { firmas }\end{array}$ & HHI & $\begin{array}{l}\text { No de } \\
\text { firmas }\end{array}$ & HHI & $\begin{array}{l}N^{N o d e} \\
\text { firmas }\end{array}$ & HHI \\
\hline (1) Menos de 50 & 11 & 2.935 & 14 & 2.978 & 11 & 6.082 & 11 & 3.194 & 8 & 5.606 & 6 & 4.369 \\
\hline (2) De 50 a 250 & 7 & 6.100 & 7 & 6.229 & 9 & 6.190 & 10 & 4.830 & 11 & 5.685 & 11 & 4.405 \\
\hline (3) De 251 a 1000 & 7 & 2.964 & 6 & 2.571 & 5 & 2.943 & 6 & 2.798 & 7 & 2.820 & 4 & 2.919 \\
\hline (4) De 1001 a 2500 & 5 & 3.025 & 3 & 5.566 & 4 & 4.409 & 4 & 4.148 & 2 & 3.432 & 2 & 3.210 \\
\hline (5) De 2501 a 4000 & 3 & 3.941 & 2 & 7.109 & 1 & 10.000 & 1 & 10.000 & 2 & 5.000 & 2 & 6.281 \\
\hline (6) De 4001 a 6000 & 1 & 10.000 & 2 & 5.083 & 3 & 3.457 & 3 & 3.858 & 3 & 3.391 & 3 & 5.766 \\
\hline (7) Más de 6000 & 1 & 10.000 & 1 & 10.000 & 1 & 10.000 & 2 & 6.455 & 2 & 6.806 & 2 & 6.993 \\
\hline Total & 18 & 3.326 & 18 & 3.623 & 16 & 3.754 & 19 & 2.666 & 17 & 2.335 & 15 & 2.550 \\
\hline
\end{tabular}

La tabla 9 muestra el índice HHI para el mercado según el tamaño de las empresas auditadas. Se puede observar, para el período de análisis que en la medida que el tamaño de las empresas auditadas aumenta, el número de sociedades de auditoría que participan es menor, lo que genera una alta concentración, llegando a constituir en los rangos más altos un monopolio en la realización del servicio. En los rangos 1 y 2 se puede observar que hay un mayor número de sociedades que brindan sus servicios, lo que hace que exista una mayor dinámica competitiva, aun cuando el $\mathrm{HHI}$ indique que el mercado está altamente concentrado. Para los rangos 3 a 7 la concentración de mercado aumenta hasta que en el rango 7 solo aparecen dos firmas de auditoría que participan en esos segmentos de empresas de mayor tamaño. Estos resultados confirman que existen barreras de entrada para las Otras sociedades en el mercado peruano, debido a que las empresas de 
mayor tamaño prefieren que las bigfour auditen sus estados financieros. Estos resultados permiten inducir que las empresas de mayor tamaño perciben una mayor eficiencia en las cuatro grandes.

TABLA 10

Cuotas de mercado de las sociedades de auditoría por tamaño de empresa auditada

\begin{tabular}{|c|c|c|c|c|c|c|c|c|}
\hline \multirow[b]{2}{*}{$\begin{array}{c}\text { Firma } \\
\text { auditora }\end{array}$} & \multirow[b]{2}{*}{ Año } & \multicolumn{7}{|c|}{ Tamaño de empresa auditada (en millones de soles) } \\
\hline & & $\begin{array}{c}\text { (1) } \\
\text { Menos de } \\
50\end{array}$ & $\begin{array}{c}(2) \\
\text { De } 50 \text { a } \\
250\end{array}$ & \begin{tabular}{|c}
$3)$ \\
De 251 a \\
1000
\end{tabular} & $\begin{array}{c}(4) \\
\text { De } 1001 \text { a } \\
2500\end{array}$ & $\begin{array}{c}(5) \\
\text { De } 2501 \text { a } \\
4000\end{array}$ & $\begin{array}{c}(6) \\
\text { De } 4001 \text { a } \\
6000\end{array}$ & $\begin{array}{c}\text { (7) } \\
\text { Más de } \\
6000\end{array}$ \\
\hline \multirow{6}{*}{ KPMG } & 2014 & $25 \%$ & $12 \%$ & $52 \%$ & $12 \%$ & - & - & - \\
\hline & 2015 & $16 \%$ & $34 \%$ & $49 \%$ & - & - & - & - \\
\hline & 2016 & $14 \%$ & $54 \%$ & $25 \%$ & $7 \%$ & - & - & - \\
\hline & 2017 & $8 \%$ & $14 \%$ & $43 \%$ & $14 \%$ & - & $21 \%$ & - \\
\hline & 2018 & $33 \%$ & $8 \%$ & $27 \%$ & $12 \%$ & - & $20 \%$ & - \\
\hline & 2019 & $6 \%$ & $12 \%$ & $21 \%$ & $11 \%$ & - & $50 \%$ & - \\
\hline \multirow{6}{*}{ PWC } & 2014 & $10 \%$ & $59 \%$ & $11 \%$ & $13 \%$ & $7 \%$ & - & - \\
\hline & 2015 & $7 \%$ & $46 \%$ & $13 \%$ & $10 \%$ & $4 \%$ & - & $20 \%$ \\
\hline & 2016 & $21 \%$ & $47 \%$ & $15 \%$ & $9 \%$ & - & $8 \%$ & - \\
\hline & 2017 & $4 \%$ & $2 \%$ & $22 \%$ & $25 \%$ & - & $12 \%$ & $35 \%$ \\
\hline & 2018 & $2 \%$ & $2 \%$ & $22 \%$ & $14 \%$ & $10 \%$ & $9 \%$ & $41 \%$ \\
\hline & 2019 & $1 \%$ & $3 \%$ & $15 \%$ & $12 \%$ & $11 \%$ & $3 \%$ & $55 \%$ \\
\hline \multirow{6}{*}{ DTT } & 2014 & $5 \%$ & $11 \%$ & $32 \%$ & $22 \%$ & $31 \%$ & - & - \\
\hline & 2015 & $7 \%$ & $14 \%$ & $43 \%$ & - & - & $36 \%$ & - \\
\hline & 2016 & $3 \%$ & $11 \%$ & $43 \%$ & - & - & $43 \%$ & - \\
\hline & 2017 & - & $44 \%$ & $56 \%$ & - & - & - & - \\
\hline & 2018 & - & $58 \%$ & $25 \%$ & $17 \%$ & - & - & - \\
\hline & 2019 & - & $40 \%$ & $28 \%$ & $32 \%$ & - & - & - \\
\hline \multirow{6}{*}{ EY } & 2014 & $6 \%$ & $10 \%$ & $25 \%$ & $4 \%$ & $17 \%$ & $7 \%$ & $32 \%$ \\
\hline & 2015 & $2 \%$ & $8 \%$ & $19 \%$ & $36 \%$ & $28 \%$ & $7 \%$ & - \\
\hline & 2016 & $5 \%$ & $6 \%$ & $16 \%$ & $17 \%$ & $25 \%$ & $7 \%$ & $24 \%$ \\
\hline & 2017 & $8 \%$ & $8 \%$ & $22 \%$ & $29 \%$ & $13 \%$ & $6 \%$ & $14 \%$ \\
\hline & 2018 & $6 \%$ & $8 \%$ & $25 \%$ & $1 \%$ & $22 \%$ & $15 \%$ & $23 \%$ \\
\hline & 2019 & $1 \%$ & $9 \%$ & $24 \%$ & $24 \%$ & $6 \%$ & $15 \%$ & $21 \%$ \\
\hline \multirow{6}{*}{ OTRAS } & 2014 & $21 \%$ & $11 \%$ & $49 \%$ & $19 \%$ & - & - & - \\
\hline & 2015 & $45 \%$ & $15 \%$ & $24 \%$ & $16 \%$ & - & - & - \\
\hline & 2016 & $18 \%$ & $41 \%$ & $27 \%$ & $14 \%$ & - & - & - \\
\hline & 2017 & $3 \%$ & $87 \%$ & $8 \%$ & $2 \%$ & - & - & - \\
\hline & 2018 & $2 \%$ & $67 \%$ & $14 \%$ & $17 \%$ & - & - & - \\
\hline & 2019 & $3 \%$ & $93 \%$ & $5 \%$ & - & - & - & - \\
\hline
\end{tabular}

Fuente: elaboración propia.

La tabla 10 muestra las cuotas de mercado de las big four y de las Otras sociedades que participan en el mercado por rangos de facturación de las empresas auditadas. KPMG tiene una fuerte presencia en los rangos 1, 2 y 3 alcanzando una cuota de mercado máxima de $54 \%$ en 2016 para el rango 2. Igualmente, tiene participación a partir del 2017 en el rango 6, es decir que en los últimos años KPMG se ha posicionado en empresas de mayor tamaño. PWC tiene participación en todos los rangos de facturación, es decir que brinda sus servicios a todas las empresas, independientemente de su tamaño. Su mayor participación está en los rangos 1, 2, 3 y 4. En 2014 obtuvo una cuota de mercado correspondiente al $59 \%$ en el rango 2. La participación en el mercado de DTT se concentra en los rangos de facturación 2 y 3, en los demás rangos tiene una escasa participación y en el rango 7 no participa. EY es la firma de auditoría que mayor participación ha tenido en todos los rangos, pero sus cuotas de participación son menores; en 2015 obtuvo una cuota del $36 \%$ en el rango 4. Estos resultados permiten inferir que EY tiene una mayor eficiencia en su servicio, independientemente del tamaño de empresa auditada.

Finalmente, las Otras firmas solo tienen participación en los primeros cuatro rangos de facturación de las empresas auditadas. Para las empresas de mayor facturación las Otras sociedades no tienen participación, lo que genera una barrera de entrada al mercado. En 2019 estas sociedades alcanzaron una cuota del $93 \%$ en el rango 2 . Si se analiza la tabla 10 desde la perspectiva de la especialización por tamaño de empresa auditada, se puede observar que KPMG y las Otras sociedades tienen una mayor participación en el rango 1 (33 \% y $45 \%$ respectivamente). KPMG, PWC, DTT y las Otras sociedades tienen una mayor participación en el rango 2 ( $54 \%, 59 \%, 58 \%$ y $93 \%$ respectivamente). Para el rango 3, KPMG (52\%) y DTT (56\%) son las que tienen mayor participación. EY (36\%) y PWC (25\%) aparecen con una mayor cuota para el rango 4. Sin embargo, en el rango 5, la cuota de mercado es más baja, donde EY (28\%) tiene un claro dominio del mercado. En el rango 6, si bien es cierto que EY tiene una relativa participación en ese segmento de mercado (15\%), ha tenido 
participación en todo el período de análisis lo que hace que haya especialización para el servicio brindado a este segmento de empresas auditadas. Finalmente, el rango 7 es dominado por PWC (55\%) y EY (32\%).

Estos resultados permiten inferir que las sociedades de auditoría se especializan por tamaño de empresa auditada, que en las empresas auditadas de menor tamaño tienen una participación activa las Otras firmas, mientras que para las empresas de mayor tamaño las big four se reparten el dominio de esos segmentos de mercado. Con estos resultados se acepta la hipótesis tercera.

El tamaño de las firmas de auditoría representa un factor fundamental para obtener ventajas competitivas. El tamaño influye en la cuota de mercado. Esto orienta a las empresas a buscar un liderazgo en el mercado, y para ello buscan reducir los costos que permitan disminuir los precios sin sacrificar los beneficios. La gestión de costos en una organización genera la aparición de economías de escala. Para estudiar la existencia de economías de escala en las sociedades de auditoría se utilizó el método de supervivencia planteado por Stigler (1968), que fue aplicado también en el mercado de auditoría en Estados Unidos por Danos \& Eichenseher (1982), mientras que García, Ruiz \& Vico (1998) la aplicaron en el mercado español y Toscano \& García (2011) en el mexicano, quienes establecieron que el tamaño de las firmas auditoras está representado por el número de auditorías realizadas y su relación con las cuotas de mercado alcanzadas.

La adaptación del método de supervivencia al estudio del mercado de auditoría, ante la ausencia de información sobre los costos de las firmas de auditoría, se da a través de la determinación del tamaño mínimo eficiente en el mercado analizando la evolución de las auditorías realizadas por cada firma en el período estudiado y su respectiva cuota de mercado. El tamaño óptimo de las firmas auditoras puede encontrarse establecido en el valor medio de auditorías realizadas, entendiéndose que en ese valor se situaría en la curva de costos medios (Tosacano \& García, 2011).

TABLA 11

Número de auditorías realizadas para el análisis de las economías de escala

\begin{tabular}{|c|c|c|c|c|c|c|c|c|c|c|c|c|}
\hline \multirow{2}{*}{$\begin{array}{c}\text { Sociedades } \\
\text { de } \\
\text { auditoría }\end{array}$} & \multicolumn{2}{|c|}{2014} & \multicolumn{2}{|c|}{2015} & \multicolumn{2}{|c|}{2016} & \multicolumn{2}{|c|}{2017} & \multicolumn{2}{|c|}{2018} & \multicolumn{2}{|c|}{2019} \\
\hline & $\begin{array}{c}\mathrm{N}^{\circ} \mathrm{de} \\
\mathrm{AR}\end{array}$ & $\begin{array}{l}\text { Cuota } \\
(\%)\end{array}$ & $\begin{array}{c}\mathrm{N}^{\circ} \text { de } \\
\mathrm{AR}\end{array}$ & $\begin{array}{c}\text { Cuota } \\
(\%)\end{array}$ & $\begin{array}{c}\mathrm{N}^{\circ} \mathrm{de} \\
\mathrm{AR}\end{array}$ & $\begin{array}{l}\text { Cuota } \\
(\%)\end{array}$ & $\begin{array}{c}\mathrm{N}^{\circ} \mathrm{de} \\
\mathrm{AR}\end{array}$ & $\begin{array}{c}\text { Cuota } \\
(\%)\end{array}$ & $\begin{array}{c}\mathrm{N}^{\circ} \text { de } \\
\mathrm{AR}\end{array}$ & $\begin{array}{c}\text { Cuota } \\
(\%)\end{array}$ & $\begin{array}{c}\mathrm{N}^{\circ} \text { de } \\
\mathrm{AR}\end{array}$ & $\begin{array}{c}\text { Cuota } \\
(\%)\end{array}$ \\
\hline KPMG & 15 & 5 & 15 & 6 & 16 & 5 & 19 & 12 & 22 & 19 & 20 & 26 \\
\hline PWC & 27 & 35 & 41 & 49 & 39 & 50 & 39 & 40 & 32 & 41 & 24 & 37 \\
\hline DTT & 21 & 14 & 14 & 9 & 10 & 8 & 5 & 3 & 5 & 2 & 4 & 2 \\
\hline EY & 34 & 43 & 29 & 33 & 33 & 34 & 31 & 31 & 24 & 18 & 21 & 22 \\
\hline OTRAS & 15 & 3 & 17 & 3 & 17 & 3 & 19 & 15 & 19 & 20 & 11 & 13 \\
\hline
\end{tabular}

Fuente: elaboración propia.

La tabla 11 muestra que a lo largo del período de análisis KPMG ganó participación en el mercado al pasar de 15 auditorías en 2014 ( $5 \%$ de cuota de mercado), a realizar 20 auditorías en 2019 (26\% de participación), con lo cual se puede establecer que el tamaño óptimo de KPMG está en el punto medio de auditorías realizadas equivalentes a 18 auditorías. Para el caso de PWC, en 2014 realizó 27 auditorías (una cuota de 35 \%), mientras que en 2019 realizó 24 auditorías (37\% de participación), teniendo un máximo de 41 auditorías realizadas en 2015 con una cuota del $49 \%$, pero luego disminuyó en los últimos dos años; con estos resultados se infiere que el tamaño óptimo de PWC puede ser el equivalente a 38 auditorías. Para el caso de DTT la evolución del servicio de auditoría disminuyó de manera significativa: en 2014 realizó 21 auditorías (cuota de mercado del 14\%) y para el 2019 solo realizó 4 auditorías (cuota de mercado del $2 \%$ ), en este caso es poco objetivo inferir el tamaño óptimo de DTT, dada las elevadas variaciones en número de auditorías y cuotas de mercado. Finalmente, EY tiene una disminución en el número de auditorías, en 2014 realizó 34 auditorías con una cuota de mercado de $43 \%$, mientras que en 2019 realizó 21 auditorías con una cuota de mercado de $22 \%$. Se puede inferir que el tamaño óptimo para el caso de EY equivale a 32 auditorías.

Estos resultados muestran que las sociedades de auditoría, sobre todo las big four, cuanto mayor es el número de auditorías que realizan, tienden a alcanzar una mayor cuota de mercado, es decir, que el tamaño 
de las firmas auditoras hace que existan economías de escala para poder ser más eficientes en costos, en un entorno de intensa competencia. Con estos resultados se acepta la hipótesis cuarta.

\section{Conclusiones}

Esta investigación tuvo como objetivo analizar la concentración de mercado de la auditoría en Perú, en el período 2014-2019. Es una primera aproximación al estudio del mercado peruano de la auditoría. Para ello, se ha recolectado la información de los honorarios de auditoría divulgados por las empresas auditadas contenidos en el Reporte sobre el Cumplimiento del Código de Buen Gobierno Corporativo. La información del honorario de auditoría es el principal aporte de esta investigación debido a la reserva con que las firmas auditoras manejan esta información. Esta información permitió analizar el mercado peruano, siguiendo la investigación de Toscano \& García (2011) para el caso mexicano.

Se concluye que el mercado de auditoría está altamente concentrado, donde las big four dominan este mercado, con una cuota conjunta que se ubica entre el $80 \%$ y $97 \%$ y con una intensidad de competencia por una mayor participación de mercado debido a la posición en el ranking establecido. Estos resultados son consistentes con la literatura científica internacional revisada que manifiesta que las bigfour son las que dominan el mercado de la auditoría a nivel mundial. Se demuestra además que las firmas auditoras están especializadas por los sectores de las empresas auditadas.

Las firmas auditoras en Perú se especializan de acuerdo con los sectores económicos donde realizan su actividad las empresas auditadas, en concreto se encontró que las firmas auditoras tienen una mayor especialización en los sectores Fondo de Pensiones, Diversas y Mineras. Por otra parte, el tamaño de las empresas auditadas se ha relacionado con los servicios de auditoría, donde existen barreras de entrada para las Otras sociedades, dado que las empresas auditadas de mayor facturación, solo contratan a las bigfour, y se demuestra que las big four se especializan por tamaño de auditoría, debido a que su participación en el mercado en todos los rangos de facturación es diferenciada, lo que supone que hay eficiencia en los procesos tendientes a brindar sus servicios tanto a empresas de menor tamaño como a compañías de mayor facturación.

Finalmente, esta investigación demuestra que las firmas auditoras trabajan con economías de escala. Tanto las bigfour como las Otras sociedades tienen una participación en el mercado en el período estudiado, unas con mayor cuota de mercado que otras. Las economías de escala pueden hacer que los procesos internos de las firmas auditoras tiendan a ser eficientes en costos para poder tener una participación sostenida en el mercado a lo largo del período de análisis. Las cuatro hipótesis que se plantearon fueron aceptadas, resultados que son consistentes con los de Toscano \& García (2011).

El dominio del mercado de la auditoría por parte de las bigfour en Perú -así como en otros países de la región- relega el desarrollo de la especialidad tanto en los profesionales como en las firmas auditoras locales, desalentando su posibilidad de competir con las grandes firmas extrajeras que, debido a su gran presencia han desarrollado tecnología y especialización en la prestación de sus servicios, lo que hace más lejano acceder a una mayor cuota de mercado de las firmas nacionales, además de la indiferencia de los entes reguladores del Perú por buscar un mayor equilibrio entre los ofertantes de los servicios de auditoría.

Los entes reguladores y supervisores del mercado de la auditoría tales como la SMV, Ministerio de Economía y Finanzas y la Contraloría General de la Republica, deberán fomentar la competitividad en este mercado mediante la creación o modificación de leyes y políticas, de esta forma se logrará evitar la desaparición de pequeñas firmas auditoras, que a pesar de contar con todos los requisitos para prestar sus servicios no logran participar en este mercado altamente concentrado.

Las firmas auditoras de menor tamaño, ante esta desventaja en el mercado, deberían llevar a cabo estrategias orientadas a la formación de consorcios, de manera que puedan hacer frente a la competencia con una mayor 
fortaleza en cuanto al capital humano, tecnología y eficiencia en costos, que permita afrontar los desafíos de este mercado.

Para comprender mejor el mercado de auditoría peruano se sugieren para futuras investigaciones desarrollar investigaciones orientadas a conocer la calidad de la auditoría realizada en relación con el honorario pagado a las sociedades auditoras, estudiar la competitividad del mercado de auditoría tomando como medida el índice de movilidad planteado por Ruiz et al (2016), las barreras de entrada al mercado y el poder de mercado.

\section{Consideraciones éticas}

Artículo derivado de la Tesis de Licenciatura en Contabilidad de la Universidad Nacional de Piura, Perú. Cumple con el código de ética interno.

\section{Contribución de los autores}

El artículo presentado fue desarrollado de manera conjunta entre los autores.

\section{Financiación}

Los autores manifestaron que no recibieron ningún tipo de financiación.

\section{Conflictos de interés}

Declaramos que ninguno de los autores tiene conflicto de intereses asociados al desarrollo de la investigación o la presentación del artículo.

\section{Referencias}

Abidin, S., Beattie, V., \& Goodacre, A. (2010). Audit market structure, fees and choice in a period of structural change: Evidence from the UK, 1998-2003. The British Accounting Review, 42, 187-206. https://doi.org/10.1016/j.b ar.2010.04.002

Asthana, S., Khurana, I., \& Raman, K. K. (2019). Fee competition among Big 4 auditors and audit quality. Review of Quantitative Finance and Accounting, 52(2), 403-438. https://doi.org/10.1007/s11156-018-0714-9

Ballas, A. A., \& Fafaliou, I. (2008). Market Shares and Concentration in the EU Auditing Industry: the Effects of Andersen's Demise. International Advances in Economic Research, 14, 485-497. https://doi.org/10.1007/s112 94-008-9167-6

Beattie, V., Goodacre, A., \& Fearnley, S. (2003). And then there were four: A study of UK audit market concentration - causes, consequences and the scope for market adjustment. Journal of Financial Regulation and Compliance, 11(3), 250-265. https://doi.org/10.1108/13581980310810561

Beattie, V., \& Fearnley, S. (1994). The Changing Structure Of The Market For Audit Services In The UK, a Descriptive Study. The British Accounting Review, 26(4), 301-322.

Bhattacharya, A., \& Banerjee, P. (2020). An empirical analysis of audit pricing and auditor selection: evidence from India. Managerial Auditing Journal, 35(1), 111-151. https://doi.org/10.1108/MAJ-11-2018-2101 
Buijink, W. F., Maijoor, S. J., \& Meuwissen, R. H. (1998). Competition in auditing: Evidence from entry, exit, and market share mobility in Germany versus The Netherlands. Contemporary Accounting Research, 15(3), 85-404. https://doi.org/10.1111/j.1911-3846.1998.tb00565.x

Carson, E., Redmayne, N. B., \& Liao, L. (2014). Audit market structure and competition in Australia. Australian Accounting Review, 71(24), 298-312. https://doi.org/10.1111/auar.12041

Carson, E., \& Fargher, N. (2007). Note on audit fee premiums to client size and industry specialization. Accounting and Finance, 47, 423-446. https://doi.org/10.1111/j.1467-629x.2007.00213.x

Ciconte, W., Knechel, W. R., \& Schelleman, C. (2015). An examination of the relation between market structure and the profitability of audit engagements. Accounting and Finance, 55, 749-781. htpps://doi.org/10.1111/ acfi. 12078

Craswell, A. T., Francis , J. R., \& Taylor, S. L. (1995). Auditor brand name reputations and industry Specializations . Journal of Accounting and Economics, 20, 297-322. https://doi.org/10.1016/0165-4101(95)00403-3

Cuesta, T. (2015). El mercado de auditoría en España. Análisis de su estructura y evolución. Tesis Doctoral, Universidad Politécnica de Valencia. https://riunet.upv.es/bitstream/handle/10251/47156/tfc.pdf?sequence=1\&isAllowe $\mathrm{d}=\mathrm{y}$

Danos, P., \& Eichenseher, J. W. (1982). Audit industry dynamics: Factors affecting changes in client-industry market shares. Journal of Accounting Research, 20(2), 604-616. https://doi.org/10.2307/2490888

Eichenseher, J. W., \& Danos, P. (1981). The analysis of industry-specific auditor concentration: Towards an Explanatory Model. The Accounting Review, LVI(3), 479-492. http://www.jstor.org/stable/246910

Eshleman, J. D., Ke, Y., \& Li, S. (2018). Custumer-Base Concentration and Audit Pricing. Journal of Accounting and Finance, 18(4), 56-79. https://doi.org/10.33423/jaf.v18i4.424

Eshleman, J. D., \& Lawson, B. P. (2017). Audit market structure and audit pricing. Accounting Horizons, 31(1), 57-81. https://doi.org/10.2308/acch-51603

Francis, J. R., Reichelt, K., \& Wang, D. (2005). The Pricing of National and City-Specific Reputations for Industry Expertise in the U.S. Audit Market. The Accounting Review, 80(1), 113-136. http://www.jstor.org/stable/4093 163

García, M. A., Ruiz, E., \& Vico, A. (1998). Análisis de la estructura del mercado de servicios de auditoría en España. VI Premio de Investigación Contable José María Fernández Pirla. Madrid: Ministerio de Economía y Hacienda, ICAC.

Gómez-Guillamón, A. D. (2001). La auditoría de cuentas en España: Un estudio empírico sobre la función, utilidad y comprensión del informe de auditoría. Tesis Doctoral, Universidad de Murcia. https://repositorio.upct.es/bit stream/handle/10317/771/adg.pdf;jsessionid=DFD64

Grigorescu, I. I. (2014). Evolución y prespectivas de la auditoría financieraen Rumanía y España: Un estudio comparativo. Tesis Doctoral, Universidad de Lleida. https://www.tdx.cat/bitstream/handle/10803/285175/T iig1de2.pdf?sequence $=2 \&$ isAllowed $=y$

Guimarães, F. G., \& Dantas, J. A. (2015). Concentracao do Mercado de Auditoria na Indústria Bancária Brasileira. Revista Evidenciação Contábil ß Finanças, 3(3), 84-103. https://doi.org/10.18405/recfin20150306

Guiral, A., \& Gonzalo Angulo, J. (2005). Informe de auditoría y comportamiento de los analista de riesgos: El modelo de revisión de creencias. Revista Española de Financiación y Contabilidad, XXXIV(125), 501-536. http://www .jstor.org/stable/42784075

Hay, D., \& Jeter, D. (2011). The pricing of industry specialisation by auditors in New Zealand. Accounting and Business Research, 41(2), 171-195. https://doi.org/10.1080/00014788.2011.550744

Hogan, C. E., \& Jeter, D. C. (1999). Industry Specialization by Auditors. Auditing: A Journal of Practice \& Theory, 18(1), 1-17. https://d1wqtxts1xzle7.cloudfront.net/50317472/Industry_Specialization_by_Auditors201611 14-13008-86xvpn.pdf?1479196326=\&response-content-disposition=inline\%3B+filename\%3DIndustry_spe cialization_by_auditors.pdf\&Expires=1619291053\&Signature=gZB1R-S6ToI9K5IY 
Huang, T.-C., Chang, H., \& Chiou, J.-R. (2016). Audit Market Concentration, Audit Fees, and Audit Quality: Evidence from China. AUDITING: A Journal of Practice \& Theory, 35(2), 121-145. https://doi.org/10.2308 /ajpt-51299

Johnson, E. N., Walker, K. B., \& Westergaard, E. (1995). Supplier concentration and pricing of Audit Services in New Zealand. Auditing A Journal of Practice \& Theory, 14(2), 74-89. https://www.researchgate.net/profile/Kenton-Walker/publication/270890268_Supplier_Concentrati on_and_Pricing_of_Audit_Services_in_New_Zealand/links/55d5e93a08aec156b9a68bca/Supplier-Concent ration-and-Pricing-of-Audit-Services-in-New-Zealand.pdf

Lopes, I. (2013). Impacto de la calidad y la transparencia de la información financiera sobre la eficiencia de los mercados. De un enfoque tradicional a un enfoque experimental. Tesis Doctoral, Universidad de Salamanca. https://gredos.usal.es/bitstream/handle/10366/122994/DAEE_lopessilva_calidadtransparenciain formacionfinanciera.pdf?sequence $=1$ \&isAllowed $=\mathrm{y}$

Martínez, A., Caso, C., \& Río, M. J. (2005). Las sociedades cotizadas y la concentración del mercado de auditoría. Partida Doble (170), 84-96. http://pdfs.wke.es/5/4/3/2/pd0000015432.pdf

Peel, M. J. (1997). UK Auditor Concentration: A Descriptive Note. Accounting and Business Research, 27(4), 311-322. https://doi.org/10.1080/00014788.1997.9729557

Pong, C. K. (1999). Auditor concentration: A replication and extension for the UK Audit Market 1991-1995. Journal of Business Finance \& Accounting, 26(3-4), 451-475. https://doi.org/10.1111/1468-5957.00263

Ruiz, E., \& Rodríguez, P. (2013). La naturaleza de la competencia en el mercado de auditoría: Una evaluación de la literatura. Revista Gallega de Economía, 22(1), 281-306. https://doi.org/10.15304/rge.22.1.1282

Ruiz, E., Rodríguez, P. I., \& Biedma, E. (2016). Barreras de entrada, concentración y competitividad en el mercado de auditoría español. Spanish Journal of Fiance and Accounting, 45(1), 92-133. https://doi.org/10.1080/0210241 2.2015.1092232

Scott, W. D., \& Gist, W. E. (2013). Forced auditor change, industry specialization and audit fees. Managerial Auditing Journal, 28(8), 708-734. https://doi.org/10.1108/MAJ-11-2012-0779

Sellers, R., \& Más Ruiz, F. J. (2008). Rentabilidad, poder de mercado y eficiencia en la distribución comercial minorista. Revista Europea de Dirección y Economia de la Empresa, 17(4), 157-170. https://dialnet.unirioja.es/descarga/a rticulo/2726977.pdf

Simunic, D. A. (1980). The Pricing of Audit Services: Theory and Evidence. Joumal of Accounting Research, 18(1), 161-190. https://doi.org/10.2307/2490397

Stigler, G. J. (1968). The Organization of Industry. Homewood, IL: Irwin.

Toscano, J. A., \& García, M. A. (2011). Estrategias de las cuatro grandes firmas de auditoría en México. Revista Europea de Dirección y Economía de la Empresa, 20(1), 89-104. https://dialnet.unirioja.es/servlet/articulo?codigo=341 6136

Van Caneghem, T. (2010). Audit pricing and the Big4 fee premium: evidence from Belgium. Managerial Auditing Journal, 25(2), 122-139. https://doi.org/10.1108/02686901011008945

Wolk, C. M., Michelson, S. E., \& Wootton, C. W. (2001). Auditor Concentration and Market Shares in the US: 1988-1999 A Descriptive Note. British Accounting Review, 33, 157-174. https://doi.org/10.1006/bare.2001.0 159

$\mathrm{Xu}, \mathrm{H}$. (2017). Differential Effects of Market Concentration on Oligopolistic and Atomistic Segments: Evidence of Audit Fees and Audit Quality. Journal of Accounting and Finance, 17(3), 121-136. https://articlegateway.com /index.php/JAF/article/view/961

Zurita, J. (2014). Análisis de la concentración y competencia en el sector bancario. Documento de Trabajo 14/23, BBVA. https://www.bbvaresearch.com/wp-content/uploads/2014/09/WP-concentraci\%C3\%B3n-y-c ompetencia-sector-bancario.pdf 


\section{Notas}

* Artículo de investigación

1 Las bigfour son el grupo de firmas auditoras que dominan el mercado de servicios de auditoría a nivel internacional. Estas firmas son KPMG, Deloitte Touche Tohmatsu Limited, Price Waterhouse Cooper y Ernst \& Young.

2 Gran parte del siglo XX los servicios de auditoria a nivel internacional eran dominados por las llamadas big eight, las ocho grandes: Arthur Andersen LLP, Arthur Young \& Co., Coopers and Lybran, Ernst \& Whinney, Deloitte Haskins \& Sells, Peat Marwick Mitchell (más tarde KPMG), Price Waterhouse y Touche Ross. En 1989, producto de la competencia se fusionan Ernst \& Whinney con Arthur Young \& Co. (Ernst \& Young) y Deloitte Haskins \& Sells con Touche Ross (Deloitte \& Touche), con lo que quedan las llamadas big six. En 1998 se fusionan Price Waterhouse con Coopers and Lybran (Price Waterhouse Coopers), quedando cinco grandes firmas auditoras. En 2002 desaparece Arthur Andersen LLP producto del escandalo financiero de la empresa ENRON, lo que genera que en el mercado queden las bigfour o cuatro grandes

\section{Licencia Creative Commons CC BY 4.0}

Para citar este artículo: Gómez, G., Sandoval, J. E., \& Poma. H. (2021). La concentración de mercado de la auditoría en Perú. Cuadernos de Contabilidad, 22. https://doi.org/10.11144/Javeriana.cc22.cmap 